\title{
3D modeling of olive tree and simulating the harvesting forces
}

\author{
Dan Ovidiu Glăvan ${ }^{1, *}$, Theoharis Babanatsas ${ }^{1}$, and Roxana Mihaela Babanatis Merce ${ }^{1}$ \\ ${ }^{1}$ University “Aurel Vlaicu” of Arad, Faculty of Engineering, 310130, Arad, Romania
}

\begin{abstract}
The paper presents the results of the study regarding the influence of shaking forces on olive tree harvesting systems. Shaking forces can be released through several methods. Important is the end result, namely the shaking force and the cadence of shaking speed. Mechanical and automatic harvesting methods collect more olives than traditional methods but may damage the olive trees. In order to prevent this damage, we need to calculate the necessary shaking force. An original research method is proposed to simulate shaking forces using a $3 \mathrm{D}$ olive tree model with Autodesk Inventor software. In the experiments, we use different shaking forces and various shaking speeds. We also use different diameters of the olive tree trunk. We analyze the results from this experiment to determine the optimal shaking force for harvesting olives without damaging the olive tree.
\end{abstract}

\section{Theoretical considerations}

Harvesting through manpower requires employing a large number of people for a limited time period, which could lead to social problems in addition to high labor costs $[1,4]$. Due to the economic and social importance of olive trees, it is necessary to use an olive-harvesting robot or an olive-harvesting automatic system, thus eliminating a big number of the human operators, who are employed in large numbers for a limited time, and increasing the speed and the volume of work $[2,3,5,11]$. In order to use an automatic system for harvesting, we must calculate the necessary force of vibration to shake the olive tree $[4,7,12]$.

For this we can use a 3D model of an olive tree based on real dimensions. We use the average diameter dimensions, which is $30 \mathrm{~cm}$ at a height of $120 \mathrm{~cm}$ in the position of the shaking dispositive and the average density of olive tree wood in raw condition is $\rho w-1.09$ $\mathrm{g} / \mathrm{cm} 3[5,8,10]$.

\section{Experimental conditions}

Before creating the 3D model, we were traveling in Greece in an olive orchard in region of Halkidiki that was designed to involve planting trees.

${ }^{*}$ Corresponding author: glavan@,fortuna.com.ro 


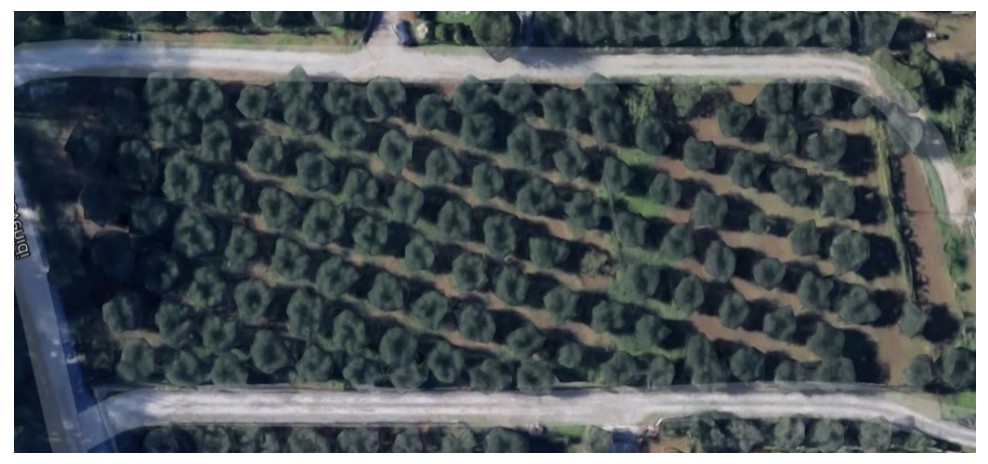

Fig. 1. Olive orchard in region of Halkidiki

Afterwards we took measurements of more than 110 olive trees (height, thickness, perimeter and number of branches). The perimeter was taken at $120 \mathrm{~cm}$ from sol where is the position of the shaking system and of the vibration forces. Once we measured more than 110 olive trees we determined the average sizes table 1.

Table 1. Olive tree measurements.

\begin{tabular}{|l|c|l|}
\hline \multicolumn{1}{|c|}{ Olive tree } & $\begin{array}{c}\text { Perimeter of olive tree (cm) at high of } \\
\mathbf{1 2 0} \mathbf{c m} \text { from sol }\end{array}$ & $\begin{array}{c}\text { Height of olive tree } \\
\text { (cm) }\end{array}$ \\
\hline 1 & 62 & 353 \\
\hline 2 & 59 & 322 \\
\hline 3 & 67 & 370 \\
\hline 4 & 65 & 341 \\
\hline 5 & 63 & 335 \\
\hline 6 & 68 & 340 \\
\hline$\ldots$ & $\ldots$ & $\ldots$ \\
\hline 112 & 59 & 294 \\
\hline 113 & 58 & 289 \\
\hline 114 & 64 & 296 \\
\hline Average dimensions & 62 & 335 \\
\hline Minimum dimensions & 53 & 258 \\
\hline
\end{tabular}

We used this data to create a 3D model. We used one 3D model: figure 2, with two sizes, one with the smallest size we found, and one based on dimensional average.

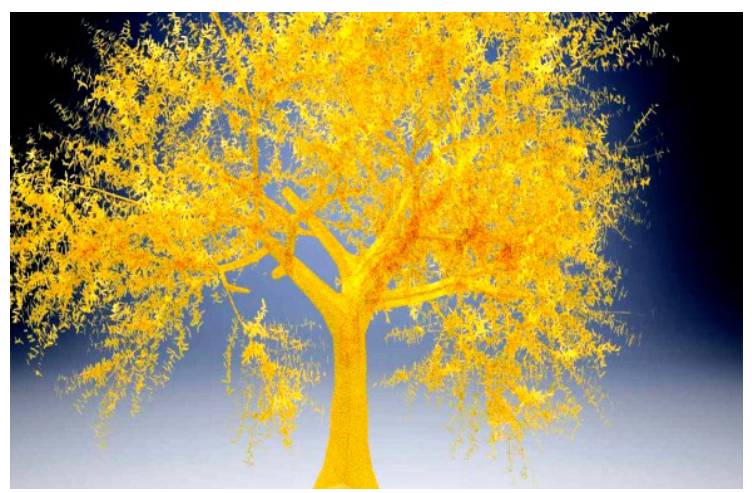

Fig. 2. 3D olive models rendering in Autodesk Inventor. 
Afterwards, we simulated different vibration forces in Autodesk Inventor analysis study, figure 3. The vibration forces were at a high of $120 \mathrm{~cm}$ in the olive tree, in positions of the shaking system $[6,9]$.

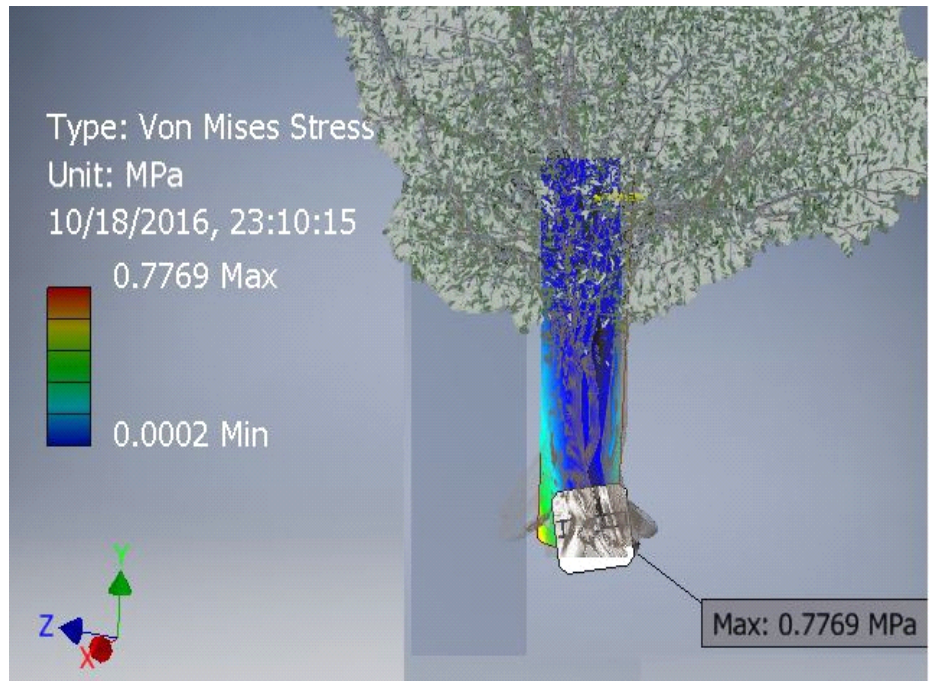

Fig. 3. Autodesk Inventor analysis.

\section{Results and discussions}

In order to determine the necessary vibration forces we can use certain software such as Inventor or Solidworks, where we can create the $3 \mathrm{D}$ model and simulate the forces. In this case, we used Autodesk Inventor with different vibration forces and statically force, table 2.

All results were satisfactory on highest forces without breaking the olive tree.

Table 2. Autodesk Inventor vibration results on olive tree wood.

\begin{tabular}{|l|l|l|}
\hline \multicolumn{1}{|c|}{ Parameter } & \multicolumn{1}{|c|}{ Minimum value } & \multirow{2}{*}{ Maximum value } \\
\cline { 1 - 2 } Volume & $176715000 \mathrm{~mm}^{3}$ & \multirow{2}{*}{} \\
\cline { 1 - 2 } Mass & $134.303 \mathrm{~kg}$ & $0.776895 \mathrm{MPa}$ \\
\hline Von Mises Stress & $0.000176446 \mathrm{MPa}$ & $0.716821 \mathrm{MPa}$ \\
\hline 1st Principal Stress & $-0.0196544 \mathrm{MPa}$ & $0.0204877 \mathrm{MPa}$ \\
\hline 3rd Principal Stress & $-0.648668 \mathrm{MPa}$ & $0.593403 \mathrm{~mm}$ \\
\hline Displacement & $0 \mathrm{~mm}$ & $15 \mathrm{ul}$ \\
\hline Safety Factor & $15 \mathrm{ul}$ & $0.134893 \mathrm{MPa}$ \\
\hline Stress XX & $-0.132117 \mathrm{MPa}$ & $0.233049 \mathrm{MPa}$ \\
\hline Stress XY & $-0.0538508 \mathrm{MPa}$ & $0.0967356 \mathrm{MPa}$ \\
\hline Stress XZ & $-0.102971 \mathrm{MPa}$ & $0.681943 \mathrm{MPa}$ \\
\hline Stress YY & $-0.622679 \mathrm{MPa}$ & $0.249304 \mathrm{MPa}$ \\
\hline Stress YZ & $-0.0697603 \mathrm{MPa}$ & $0.272747 \mathrm{MPa}$ \\
\hline Stress ZZ & $-0.296653 \mathrm{MPa}$ & $0.314307 \mathrm{~mm}$ \\
\hline X Displacement & $-0.000801034 \mathrm{~mm}$ & $0.0453073 \mathrm{~mm}$ \\
\hline Y Displacement & $-0.0455565 \mathrm{~mm}$ & $0.501298 \mathrm{~mm}$ \\
\hline Z Displacement & $-0.00139634 \mathrm{~mm}$ & $0.0000634389 \mathrm{ul}$ \\
\hline Equivalent Strain & $0.0000000128804 \mathrm{ul}$ & $0.00000219895 \mathrm{ul}$ \\
\hline 1st Principal Strain & $-0.0000697494 \mathrm{ul}$ & \\
\cline { 1 - 2 }
\end{tabular}




\begin{tabular}{|l|l|l|}
\hline 3rd Principal Strain & $-0.000014206 \mathrm{ul}$ & $0.0000145032 \mathrm{ul}$ \\
\hline Strain XX & $-0.000014206 \mathrm{ul}$ & $0.0000145032 \mathrm{ul}$ \\
\hline Strain XY & $-0.00000579099 \mathrm{ul}$ & $0.0000250616 \mathrm{ul}$ \\
\hline Strain XZ & $-0.0000110733 \mathrm{ul}$ & $0.0000104027 \mathrm{ul}$ \\
\hline Strain YY & $-0.0000669544 \mathrm{ul}$ & $0.0000733271 \mathrm{ul}$ \\
\hline Strain YZ & $-0.00000750186 \mathrm{ul}$ & $0.0000268095 \mathrm{ul}$ \\
\hline Strain ZZ & $-0.0000318973 \mathrm{ul}$ & $0.0000293271 \mathrm{ul}$ \\
\hline
\end{tabular}

The harvest forces taken into consideration in the present paper were validated by the virtual model simulated in Autodesk Inventor, results being part of a previous paper already presented in another Conference.

The researches will continue by creating a real model of harvesting device with adjustable forces that will confirm or not our presumptions and aloud us to establish closer values for forces closer with the real situation.

\section{References}

1. Debojit, Biswas Jain Hitesh, K. Arora Manoj, R. Balasubramanian, International Journal of Earth Sciences and Engineering, 4, 6 (2011)

2. M.Z. El Attar, M.N. El Awady, M. Rashwan, M.A.I. Genaidy, Proceedings of the 10th MSAE Conference (2004)

3. D. Mnerie, D. Tucu, A. Golimba, G. Anghel, Proceedings of the 36th International Symposium "Actual tasks on agricultural engineering", Opatija, Croatia, 617, 36 (2008)

4. C. Peri, Olive handling, storage and transportation (Wiley-Blackwell, 2014)

5. C. Peri, The extra virgin Olive Oil Handbook (Wiley-Blackwell, 2014)

6. D. Tucu, Proceedings of the 39th International Symposium "Actual tasks on agricultural engineering", Opatija, Croatia, 171, 39 (2011)

7. D. Tucu, Proceedings of the 40th International Symposium "Actual tasks on agricultural engineering", Opatija, Croatia, 549, 40 (2012)

8. D. Tucu, Proceedings of the 40th International Symposium "Actual tasks on agricultural engineering", Opatija, Croatia, 405, 42 (2014)

9. D. Tucu, A. Filipovici, Proceedings of the 40th International Symposium "Actual tasks on agricultural engineering”, Opatija, Croatia, 397, 42 (2014)

10. D. Tucu, A. Golimba, D. Mnerie, Proceedings of the 40th International Symposium "Actual tasks on agricultural engineering", Opatija, Croatia, 447, 38 (2010)

11. D. Tucu, A. Golimba, T. Slavici, Proceedings of the 40th International Symposium "Actual tasks on agricultural engineering", Opatija, Croatia, 455, 38 (2010)

12. K. Wang, J. Yang, G. Shi, Q. Wang, Proceedings of the Fourth International Conference on Natural Computation, ICNC '08, Jinan, China (2008) 